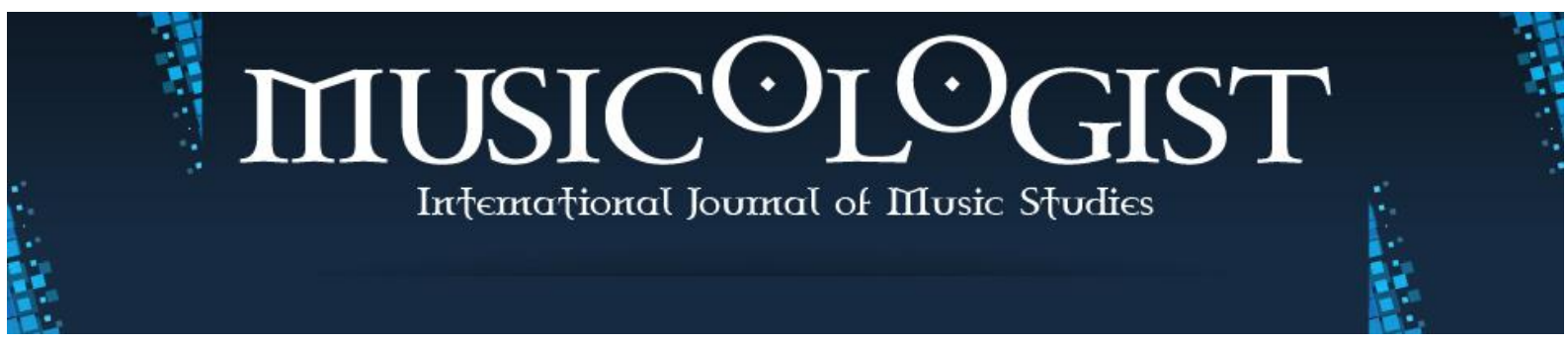

Trabzon University State Conservatory @ C 2017-2020

Volume 4 Issue 2 December 2020

Research Article

Musicologist 2020. 4 (2): 168-197

DOI: 10.33906/musicologist.782185

\begin{abstract}
NANA MZHAVANADZE
Universität Potsdam, Germany

mzhavanadze@uni-potsdam.de

orcid.org/0000-0001-5726-1656
\end{abstract}

FRANK SCHERBAUM

Universität Potsdam, Germany

fs@geo.uni-potsdam.de

orcid.org/0000-0002-5050-7331

\title{
Svan Funeral Dirges (Zär): Musicological Analysis
}

\begin{abstract}
This paper is a companion paper to Scherbaum \& Mzhavanadze (2020). Jointly, the papers describe the results of an interdisciplinary study on three-voiced Svan funeral dirges, known as zär in Svan and zari in Georgian. In the present paper, to which we refer as paper 2, we focus on the (structural) musicological aspects of zär. Bluntly speaking, we want to obtain a basic understanding of 'how zärs work'. Based on the results of the acoustical analysis of a new collection of field recordings from eleven different performances described in paper 1 , where we developed a phenomenological description of the general building blocks, here we try to derive a simple model for the syntaxes of $z a ̈ r$.

The complexity of the musical structure of the zär shows a very clear connection to the history of the Svans' settlement along the Enguri River, which is obviously systematically reflected in the Svans' music.

Finally, we see the most interesting aspects of our entire study in the implications it has for the discourse on the historical dynamics of Georgian polyphony. Thus, the results of our study challenge the generally accepted view of the development of Georgian traditional music from monophony to polyphony.
\end{abstract}

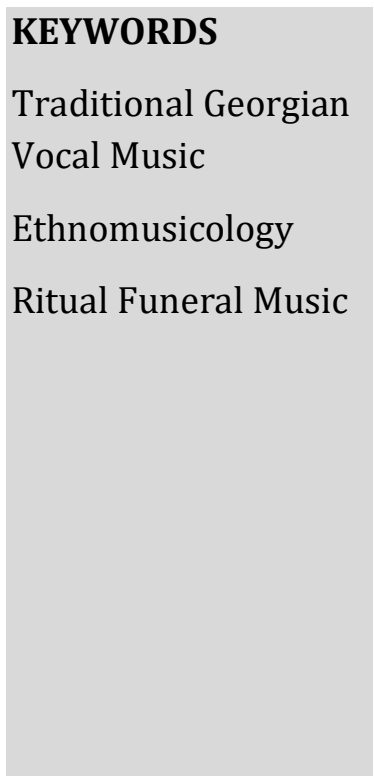




\section{Introduction}

To understand zär's musical syntax, we did a musical analysis of it, trying to cover as many aspects as possible. On one hand, we did this through a (holistic) form analysis including its static compositional structure, in order to delineate its formal 'boundaries' and to observe the dynamics of its implementation (in time). On the other hand, we analyzed musical elements such as melody, harmony, rhythm, and verbal text in order to determine the musical content of the internal structural elements (phrases, cadence formulas, pitch and interval inventory, etc.). The combination of the results of the structural analysis with the contextual data (ethnographical, sociological, geographic, etc.) was used to achieve a more holistic understanding (in the sense of the methodology of "holistic analysis" by Mazel (1960), Zuckermann and Mazel (1967) and Zuckermann (1970). However, we are aware that we were unable to cover all of its features (for example, timbre, style). In addition, such aspects of analysis as "analysis as a practical aesthetics" (Kholopov, 1985:131) were used for the qualitative evaluation of musical elements. The purpose of this was to observe how Svans understand and employ these elements in their musical language. For example, we learned that while the harmonic fifth forms the 'building' frame of the compositional structure, the harmonic fourth seems to carry a more aesthetic meaning, emphasizing emotional tension. Thus, despite our attempts to analyze the musical elements as objectively as possible, we had to label them (for the above reasons), which therefore still reflects our interpretation (in the sense of Heidegger).

Although we use classical music terminology to describe and discuss the musical components of zär (e.g., unison, fifth, fourth, octave, melody, etc.), we want to note that these terms are not conceptually identical to their European classical music equivalents. For example, interval names are used to help you orientate better by formally linking them to intervals in classical music. In fact, however, these intervals, on one hand, reveal less strictly defined acoustic limits, and on the other, their functional applications in Svan music (zär) are based on their own rules.

Considering that the zär is an integral part of the Svan funeral rite (in other cases it is strictly forbidden to perform it), the ritual perspective of studying the phenomenon is important. If we theorize a complex of components of the funeral rite that embody the 
Svan understanding of death, then zär can be viewed as a liminal relic of 'being' (cf. 'zsmcosszsmgzs' is the Georgian word for 'death', which means change of form and

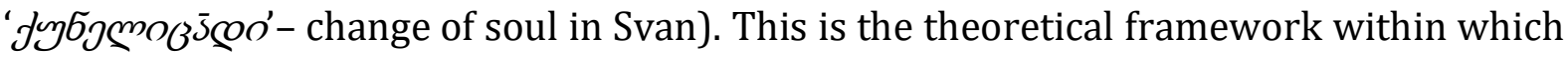
ethnomusicologists would study zär. However, while we considered broader contextual data (ethnographic accounts and local understanding of death) in interpreting the results of our musical analysis, we had to focus on a more specific musical perspective within the presented format. Thus, by trying to shed more light on the musical syntaxes, we hope to complement other perspectives. ${ }^{1}$

In paper 1 (Scherbaum \& Mzhavanadze, 2020), we have performed an acoustical analysis of the zär corpus, which we recorded in 2016. In the course of this analysis, we aimed at the determination of the pitch inventories and the melodic and harmonic interval inventories used by the singers. While this is important musical information in its own right (e.g., to describe the tuning system), it only provides the acoustical skeleton on which the musical structure of zär is built. In contrast, in the present paper, we try to describe the musical structure itself. This is a challenging task, particularly from a computational perspective. As one can easily see (and hear) from the recorded material ${ }^{2}$, the music lacks explicit rhythm, ${ }^{3}$ which ruled out the use of commonly available tools to detect strong and weak beats algorithmically. In addition, the absence of clearly expressed melodic contours, the very slow tempo, and almost equally distributed pitch lengths, combined with more or less constant intensity of vocal production, make it difficult to find acoustical patterns that would help to algorithmically decipher the temporal structure. Though in computer visualization of songs it is possible to notice a certain temporal structure (e.g., Figure 10), we could not find a consistent way to determine the relevance of these visually identifiable elements concerning musical structure of zär. Therefore, we decided, as a first step of our analytical chain, which is shown in Figure 13, to approach the problem from a perceptional perspective. Since the

\footnotetext{
${ }^{1}$ Given the importance of the understanding of the cultural context of $z a ̈ r$, in addition to the discourse in paper 1 (Scherbaum \& Mzhavanadze, 2020) we are providing two related documents from our field work in 2016 at: https://www.unipotsdam.de/fileadmin/projects/soundscapelab/PapersMusic/2020/Z\%C3\%A4r V0 Final2.pdf (Mzhavanadze \& Scherbaum, 2020) and https://lazardb.gbv.de/detail/9168 (Scherbaum \& Mzhavanadze, 2018).

${ }^{2}$ https://www.audiolabs-erlangen.de/resources/MIR/2017-GeorgianMusic-Scherbaum

${ }^{3}$ Some subtle rhythmical features in zär have been observed to be generated implicitly, for example through the use of particular vowel sequences, e.g. i-e-o or articulation style. This is the subject of an ongoing separate study.
} 
first author (N.M.) is an experienced singer with a long-standing exposure to Svan music (which helps to observe the music partly from the point of view of the locals), she immersed herself deeply in zär's recordings, listening to them over and over again trying to absorb musical texture as a musician. This eventually led to the perceptional recognition of the phrases and their inner structure (motives, smaller units within these phrases). Once she felt that she had fully absorbed the music on a perceptional level, she performed a classical transcription into European music notation system (in XML format) (Figure $13 c^{4}$ ). What was important in this context, was that in the process, she manually corrected the significant continuous shift in pitch in the performances. Based on these transcriptions, she performed a structural analysis. In this context, it was absolutely important to detect the tonal center, ${ }^{5}$ and how it changes during singing, because phrases and micro phrases, it turned out, were built around it. In addition, she tried to identify and mark all cadences, bridges and jumps.

Subsequently, from this digital score, a harmonic melograph ${ }^{6}$ was calculated, which allows to visualize the melodic and the harmonic content of a three-voiced song in a single plot (Figure 13e). However, in this context, for the color coding of the harmonic intervals, we made use of the fact that the music is non-tempered and that harmonic thirds, sixths, and sevenths are neither major nor minor, but can best be described by distributions with a certain spread, centered on pitches somewhere - in western language - between minor and major (c.f. Figure 11 of paper 1). To conceptualize (in Figure 13e), we color coded 3 rds, 6 ths, and sevenths as neutral intervals.

\footnotetext{
${ }^{4}$ To facilitate the comprehension of the figures and their relation to each other, their numbering has been continued from paper 1.

${ }^{5}$ Here we use the terms "tonal center" (TC) and "main tonal center" (MTC) in the sense of Reck $(1977,277$ 279), to describe pitch values, which carry a particular functional weight within the tonal organization. According to Reck these can be established in various ways: e.g., by emphasis, repetition, harmonies or by drones. In zär the MTC is maintained by the bass voice and undergoes only a few temporary shifts (transpositions) the magnitudes of which vary from one to three degrees downwards and one degree upwards (depending on the variant). Therefore, when the weight shifts from the main tonal center to another degree, we call the latter a temporary tonal center (TTC). The difference between the two is referred to as relative mode level.

${ }^{6}$ The harmonic melograph is a visualization technique, which displays the melodic and harmonic information content of a three-voiced song in a single plot by color coding the spaces between pairs of two voices according to the corresponding harmonic interval sizes between them.
} 
a)

Acoustical analysis

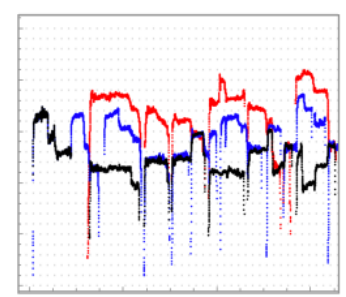

b)

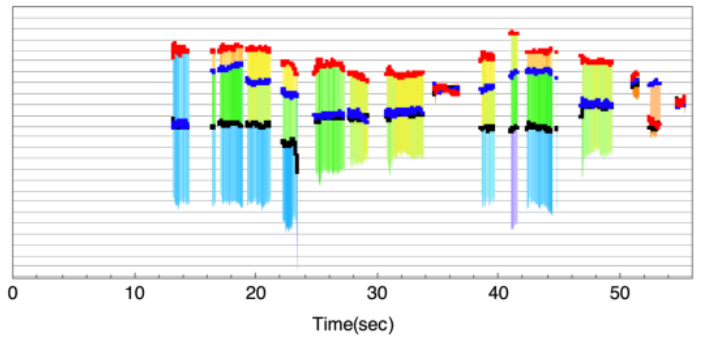

$\square 0=100 \square 200 \square 300 \square 400 \square 500 \square 600$ $\square 700 \backsim 800 \square 900 \square 1000 \square 1100=1200$
Perceptional analysis
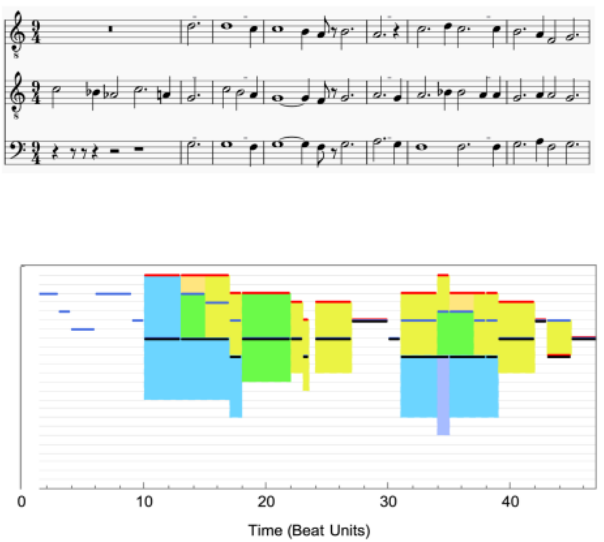

d)

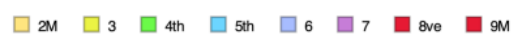

Figure 13. The principle of the generation of harmonic melographs by acoustical analysis (left panel) and by computer-aided perceptional analysis (right panel). a) Waveform of the first 60 seconds of the Ushgul zär. b) Corresponding fundamental frequency (F0) trajectories for the three voices. c) Transcription of the first 60 seconds of the Ushgul zär. d) Harmonic melograph plot corresponding to the polyphonic part of b). e) Harmonic melograph derived from the digital score shown in c).

As a result of this process, to which we refer as computer-aided aural transcription, we have obtained a new type of visualizations of the musical structures of the analyzed zär, which are close in their acoustic properties, such as the melodic contours of individual voices and the content of harmonic intervals - similar to the plots of harmonic melograph presented in paper 1 (cf. Figure 13d and e) - but based on the aural transcription of an experienced singer and trained (ethno)musicologist. As a consequence, this visualization concept is the same as in paper 1, except that here it should be seen as a conceptual representation of what has been perceived and not, as in paper 1, only what has been measured. These plots finally helped us to visualize and analyze the temporal development of zär and decipher their inner harmonic and melodic structure as detailed in the next section. 


\section{The 'compositional' structure of zär}

Independent of the duration of a zär, which ranges from approximately 2.5 to $5 \mathrm{~min}$, a human listener, even on first hearing, will perceive some obvious structural characteristics, e.g. that each zär is introduced by a short monophonic part, sung by the middle voice. This monophonic introduction (call) seems to encode the whole concept of the chant, both in musical and verbal aspects. It prepares the zär group of performers for 'what' (which variant) will be sung and serves as a compressed synopsis for the dirge. ${ }^{7}$ In other words, it contains all the important information about this variant. The tonal range of the introduction introduces the ambitus of the dirge and to some extent prepares the vertical framework. It also introduces the main tonal center (MTC) ${ }^{8}$ around which the group should build their parts and also introduces the articulation style (e.g., intense or soft). In addition to their structural role, the introductions may also contain valuable information concerning the interpretation of the ritual 'function' of zär, which will be discussed in detail in section 4 .

Once the introduction has served its purpose (which usually takes 10-15 seconds), the polyphonic part starts with the first phrase by introducing a perceptionally very strong harmonic framework of parallel fifths. In the polyphonic segments, voices never cross (only in rare cases of some cadences), but merge from time to time. In other words, the voices of zär move ${ }^{9}$ in chords, which, therefore, has been referred to as chordal unit polyphony (Aslanishvili, 2010) or synchronous polyphony (Gabisonia, 2007). ${ }^{10}$

\footnotetext{
7 To avoid confusion with using the controversial terms such as: keening, lamenting, wailing, crying, etc. applied to describe ritualized mourning soundscape, in the article we will employ the keening for all types of mourning sound manifestations based on improvisational expression of sorrow over loss (solo, responsorial, etc.) and dirge (or chant) for organized polyphonic phenomena such as zär. This will put clear line between two distinctive and radically different ritual mourning styles sharing the same functional locus.

${ }^{8}$ Here we use the term 'main tonal center' (MTC) in the sense of Reck $(1977,277-279)$, to describe a pitch value, which carries a particular functional weight within the tonal organization. According to Reck these can be established in various ways: e.g. by emphasis, repetition, harmonies or by drones. In zär the MTC is maintained by the bass voice and undergoes only a few temporary shifts (transpositions) the magnitudes of which vary from one to three degrees downwards and one degree upwards (depending on the variant). Therefore, when the weight shifts from the main tonal center to another degree, we call the latter a temporary tonal center (TTC). The difference between the two is referred to as relative mode level.

9 The word 'movement' should be taken with a grain of salt, as in reality sometimes voice may not move, but through the articulation of the same pitch with different vowels/syllables creates an illusory impression of movement (motion).

10 While classifying the polyphonic forms of the Svan repertoire, some Georgian scholars describe it as chord polyphony, meaning that all three voices move synchronously and predominantly in parallel in time.
} 
In addition, overall pitch may start to gradually rise. This has been observed for some of the performances described in paper 1 and may lead to overall pitch differences of up to 500 cents (a fourth) between the beginning and end of a zär, regardless of the duration of the dirge. Since it is obvious that this phenomenon depends not on the variant but on who makes it (the variant), we do not consider this a structural effect.

Structurally, the group (three-voiced) parts of the zär consist of sequences of repeated and elaborated phrases, which, in turn, consist of typical musical elements such as motifs, different types of cadences, bridges, and leaps. In the next two subsections, these elements and the way they work together are discussed for two selected variants, the Ushgul zär and the Lat'li zär.

\section{The K'äl-Ushgul zär}

Figure 14 shows the harmonic melograph plot for the K'âl-Ushgul zär. The skeleton of the plot is built by the melody contours of the three voices that are shown by the red, blue, and black solid line segments for the top, middle, and bass voices, respectively. As the time unit we use the beat units from the transcription part of the processing chain Figure 13c. The spaces between the melody contours of the top and middle voices and between the middle and the bass voices are color coded according to the corresponding harmonic intervals. The intervals between the bass and the top voices are displayed as color coded mirror images (hanging below the melody contour of the bass voice). 


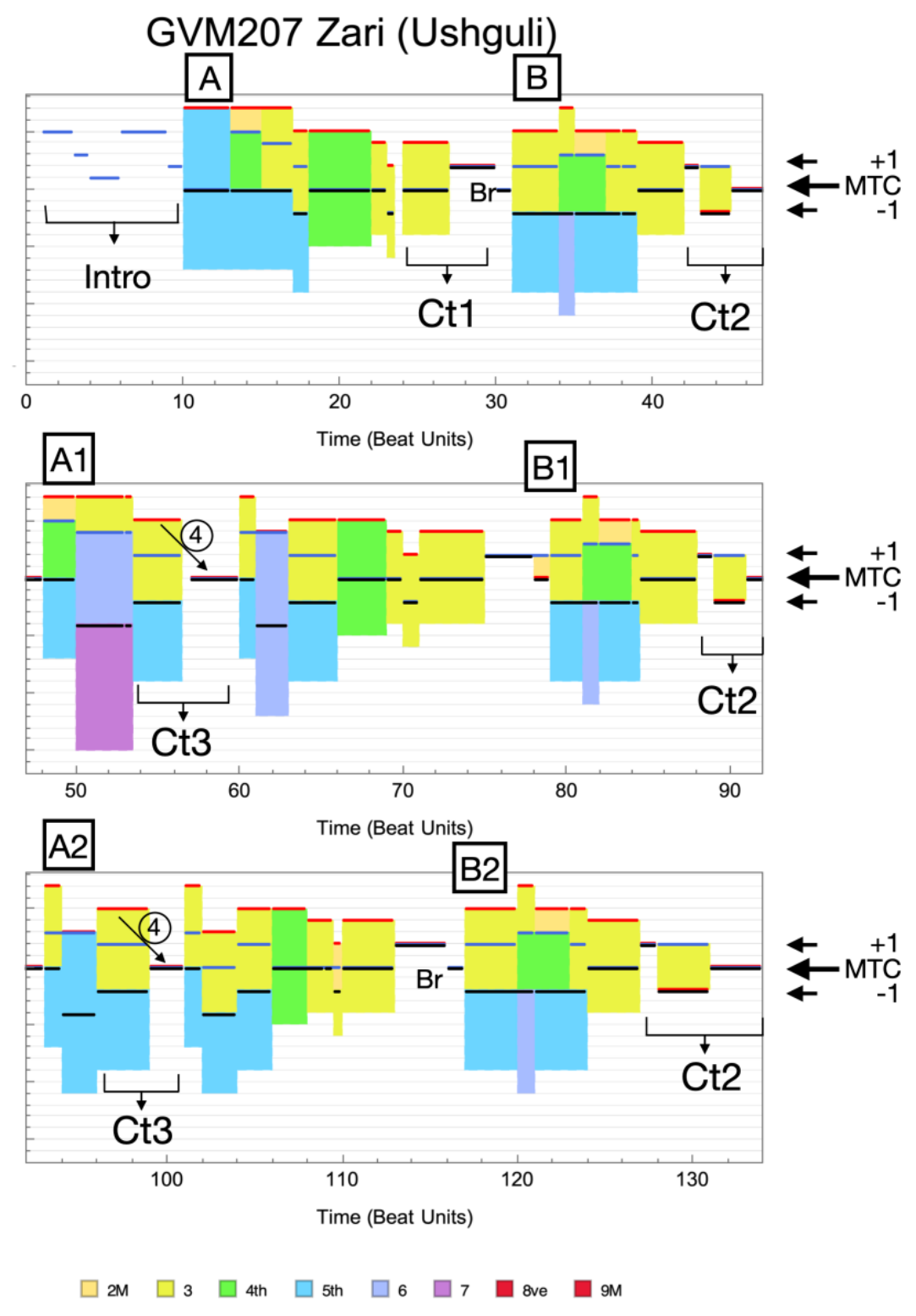

Figure 14. Visual representation of the 'compositional' structure of the K'âl-Ushgul zär (GVMID207) as harmonic melograph, superimposed by the structural elements described in the text.

What is important to note regarding the color code used for the harmonic intervals is that the thirds, sixths, and sevenths are not divided into minor or major intervals. This reflects their acoustical properties discussed in paper 1, e.g., that the distribution of thirds usually have a very large dispersion in comparison to the so-called pure intervals (fourth, fifths, and octaves). As a consequence, the color codes of thirds, sixths, and sevenths correspond to their neutral values $(350,850$, and 1050 cents). This should only be seen as a conceptualization.

Figure 14 contains all the basic building blocks and some of the mechanisms used by the Svans to construct and shape all the recorded zär. Visually, the most obvious structural 
units are what we refer to as phrases, which are indicated in Figure 14 by framed letters (A, B, A1, B1, A2, B2). Each phrase ends through a closing formula, a cadence, which appear in the Ushgul zär in three different varieties, labeled Ct1, Ct2, and Ct3. ${ }^{11}$

As already mentioned above, the first temporal segment of any zär is a melodic introduction (labeled as Intro in Figure 14) that initiates the main tonal center (MTC) and signals which variant of zär is proposed to be performed. It is the middle voice that introduces and repeatedly confirms the MTC. The moment when the middle voice initiates the MTC simultaneously marks the point at which the polyphonic part begins, with the upper and bass voices joining the middle voice at the MTC. For the Ushgul zär this happens at beat unit 10 (Figure 14). The first phrase (A) begins with the MTC pitch and ends with the first type of cadence (Ct1). At the beginning of $\mathrm{Ct} 1$, the middle voice meets the bass voice at the MTC. In the subsequent note, all three voices come together at a pitch level which is one degree above the MTC pitch. We call this pitch level relative mode degree (RMD) level +1 . Phrase B starts with a short bridge (labelled Br) where the bass and the middle voice briefly come together on the MTC pitch before the bass voice moves to the RMD level -1 and the zär becomes fully polyphonic again. At the end the second phrase (B) returns to the MTC via the second type of the cadenza (CT2), in which the final unison is reached at the MTC pitch via a movement from a unison at RMD level +1 , followed by a short two-voice segment, where the top and the bass voices come together at RMD level -1 , while the middle voice stays at RMD level +1 . As a consequence, the penultimate harmonic interval is a $3 r d$.

The first two phrases already convey the main musical content of the whole dirge, incorporating all the basic music-making features, such as the main tonal center, bridges and cadences and, therefore, conceptualizes the whole model. In the third type of cadence (Ct3), which is realized in the subsequent phrase (A1), the final unison is reached through a downward jump of one of the voices by a melodic fourth (marked with a tilted downward arrow, which is labelled by an encircled 4). These downward leaps by a melodic fourth appear also as an intra-structural feature as will be discussed in more

\footnotetext{
${ }^{11}$ Although, despite the fact that in zär we observe some types of cadences, which Arom and Vallejo (2010) describe based on the analysis of the entire Georgian repertoire, we have classified them somewhat differently.
} 
detail below ${ }^{12}$. Phrases A1 and B1 repeat and alter the basic structures of phrases A and B. By the end of phrase A1, the pitch of the tonal center has shifted to RMD level +1 .

Thus, the compositional structure of the K'âl-Ushgul variant is based on the repetition method and leads to the following sequence of phrases: A, B - A1, B1 - A2, B2. The whole chant is held together by the main tonal center (MTC), which begins and ends the polyphonic part. It also shows that the tonal center can shift temporarily to pitches which are one above and below the MTC pitch.

Since the K'āl-Ushgul zär is the shortest of all zär in duration, the phrases are also very short, and therefore they represent a chain of pure cadences. However, despite the short duration, the K'āl-Ushgul zär reveals a compressed model of almost all types of events that occur in more advanced versions. For example, in the first cadence (Ct1) of the first phrase, the main tonal center is shifted one step higher (to RMD level +1 ), although in other variants such shifts occur only at the very end of the chant and never before, as in the Ushgul variant. Therefore, it seems that the first phrase (A) is an embryonic model of the structure containing/compressing all the structural and compositional features of $z a ̈ r$, which was later developed and advanced in different directions, including the K'ālUshgul zär itself (for example, the cadence Ct3). In other words, the first phrase of the K'âl-Ushgul zär already contains the completeness of the form: the main tonal center, temporary tonal centers and the shift upward with the full cadence in unison.

\section{The Lat'li zär}

The Lat'li zär (Figure 15) is a vivid demonstration of one of the extended (advanced) variants of the main compositional structure of zär. Besides, it is the only surviving example of a hidden two-choir (antiphonal) shape of the dirge, information about which has been preserved in historical sources (Paliashvili, 1909: 8-9). Today zär is performed by a single group and we did not expect to find any antiphonal variants. But when analyzing the recordings, although Lat'li zär is performed by only a single group, an indepth observation of the structure revealed features that may serve as evidence, supporting the hypothesis that in the past it was performed by two choirs. In fact, the structure can be divided into two equal parts, each of which has a vocation (introduction

\footnotetext{
12 It should be noted here that this type of cadence (Ct3) is typical for hymn-type Svan ritual songs.
} 
call), and the second part is almost identical to the first part. In other words, almost all the phrases are repeated in the second part, which ends with a coda. Such antiphonal performance of $z a ̈ r$, however, may be connected not only with the same variant, 'sung' by two choirs (which has been lost today), but also with the tradition of performing different variants of zär by different choirs in a row (when one choir performs one variant from one village, and another variant from another village follows). This type of antiphonal singing can sometimes be heard today. ${ }^{13}$

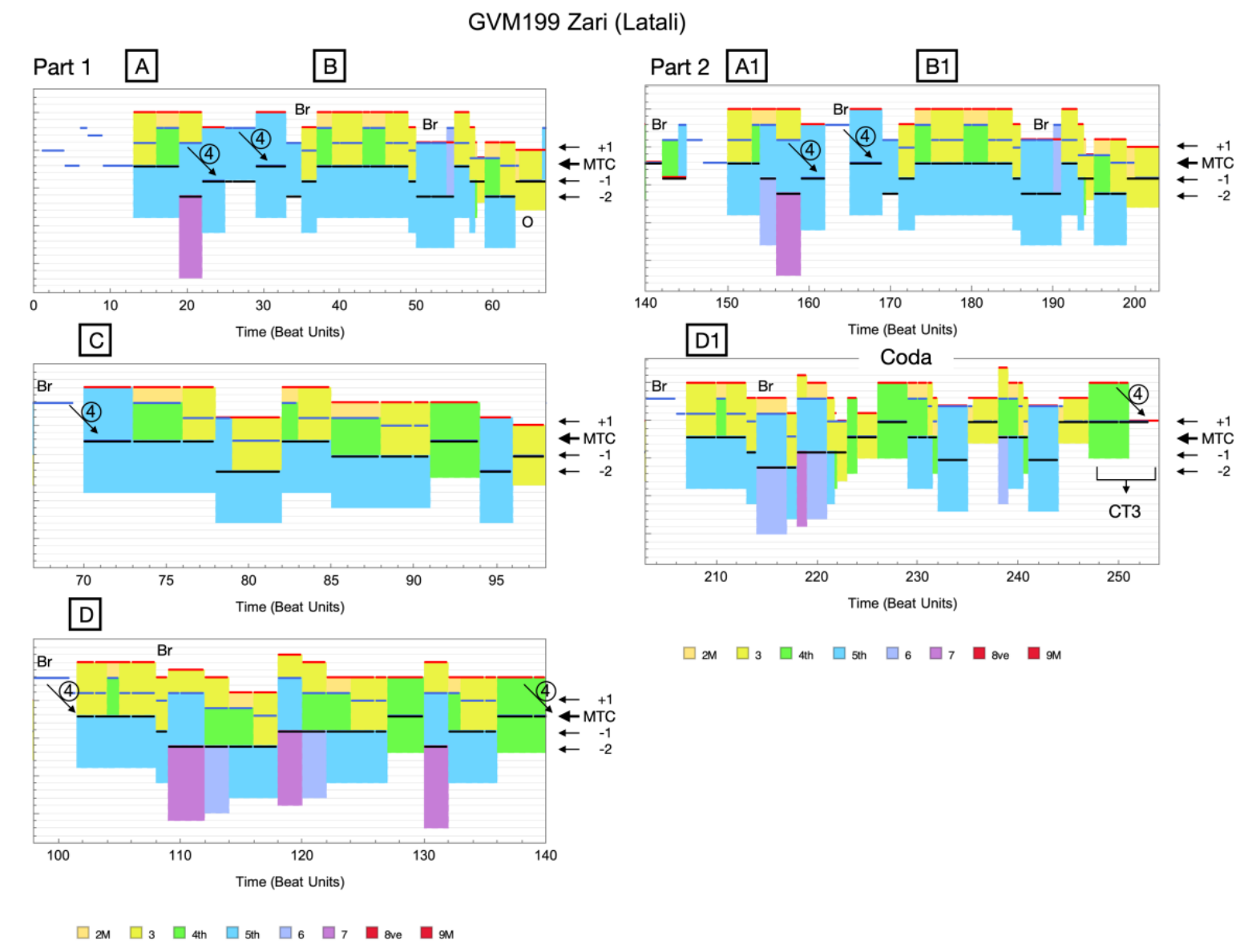

Figure 15. Visual representation of the 'compositional' structure of the Lat'li zär (GVM-ID199) as harmonic melograph, superimposed by the structural elements described in the text.

The structure of the first part (Part 1 in Figure 15) can be formulated as follows: Introduction, A, B, C, D, followed by a final cadence of the third type (Ct3) followed by a bridging step-down movement in top and bass voices, and then again, a call in the middle voice. In the second part (Part 2 in Figure 15) the structure of the first part is repeated sometimes with very slight variations in the following sequence: A1, B1, D1. The whole

${ }^{13}$ Antiphonal singing is characteristic of Georgian traditional music in general. 
chant concludes with a coda, wherein the tonal center shifts to one degree above the MTC pitch. Such a shift of the tonal center in the final phrase is observed in all zär variants except in K'āl-Ushgul (here it occurs in the very first phrase). As for temporary tonal center changes inside the phrases, they reflect the same pattern and in addition, select new (temporary) tonal centers down to two degrees away from the MTC. This extends the ambitus of the chants and makes the musical texture of the phrases more complex.

In addition to the increased number of temporary tonal centers, the complexity of Lat'li $z a ̈ r$, as well as of all other variants (except K'àl-Ushgul zär), manifests itself in the types of endings of phrases (cadences), creating the impression of a continuous musical dramaturgy with more vague phrase boundaries. This continuous movement of the musical narrative is achieved through open ends of phrases before the final end of the structure. In contrast to the variant of K'āl-Ushgul, a closed cadence takes first place at the end of the first part, followed immediately by a bridge movement allowing a new call to begin the second part ('second' chorus) and then at the very end of the whole dirge ending one degree above the MTC.

When we talk about 'open ends' here, we mean that unlike the main tonal center, temporary tonal centers (TTC) are not reinforced and are not repeated by (full/unison) cadences. ${ }^{14}$ Each arrival of a temporary tonal center simultaneously serves as a transition to a new temporary tonal center or as an arrival to the main tonal center (Figure 15).

As mentioned earlier, the boundaries between phrases are also marked by leaps. In other words, broad melodic steps are not typical for intra-phrasal movements. As in the K'ālUshgul variant, leaps indicate only transitional steps or initial/end parts of phrases. The transient/bridge steps are usually performed a fifth above TTC to provide a natural transition back to the MTC from one degree below.

Such changes of tonal centers, on one hand, help enrich the musical idea by adding new colors to the phrases, and on the other hand, have a pronounced compositional function. For example, temporary shifting of a tonal center by one step down indicates that it is not the end yet, and predicts a new beginning (Lat'li zär, between the first and second part). In contrast, a shift to one degree above the MTC indicates the end of the chant for all zär

\footnotetext{
14 We speak about closed cadences which end in unison.
} 
variants except $K^{\prime}$ àl-Ushgul ${ }^{15}$. At the same time, it also reinforces the emotional state (mode), in combination with other expressive tools, such as the persistent emphasis on certain concomitant intervals (fourth+fifth in Lat'li zär, or the interval of fourth in the Mest'ia zär, for example), articulated by verbal exclamations with strong mourning connotation (semantic meaning). Thus, the last part in form of a 'coda', which confirms the transposition one degree above MTC, also represents the emotional and compositional peak of the chant.

The above-described musical phrases, separated by cadences, especially in advanced samples, consist of smaller, nucleus units, the combination of which constitutes these phrases. These units often serve to confirm the tonal centers by means of short cadences. Such small nuclei and micro-phrases (motives) can also be detected, as we stated earlier, via some articulation features, which seem to matter as a form-detecting tools. A simple and intuitive visualization of this is shown in Figures 3a) and b) of paper 1. Indeed, we can see that the sliding phases up and down coincide with the boundary contours of structural units. Some of them are very symmetrical and applied by all voices simultaneously. This suggests that, despite the absence of explicit markers for detecting strong and weak beats and metric and rhythmic boundaries, the manner of articulation, expressed in deep slides up and down, shows what the notion of a smallest unit of the phrase for performers is (see Figure 3 of paper 1 ).

\section{The tonal organization of zär}

In the following section, we are going to discuss the main musicological aspects of the tonal organization of zär, as they reveal themselves in the results of the acoustical analysis, described in paper 1 . In the first place, this concerns the melodic and harmonic tuning systems (pitch and interval inventories) employed by the particular ensembles, and how they are used to shape the musical texture of zär. Metaphorically speaking, we are moving from the shape of the 'compositional' skeleton of $z \ddot{r}$, to what one could call its texture.

\footnotetext{
15 The latter explains the reason why, for example ch'uniri (folk bowed string instrument) players, every time after the end of singing suddenly play a step up with the instrument to finish with. This seems to be a stylistic feature that points to the end of the song.
} 


\section{Pitch inventories}

As described in detail in paper 1 , some of the ensembles performed with a gradual pitchrise, which leads to considerable pitch differences between the start and the end of the $z a ̈ r$. Since the pitch rise is mentally ignored for the perception of the melodic progression, it also has to be corrected (as described in paper 1) in the context of determining the perceived pitch inventories (technically speaking these are F0 value histograms). Figure 11 (in paper 1) shows the results of overall F0 value distributions for each zär, thus demonstrating the diversity of shapes that seem to be changing systematically from Ushgul to the Lower Bal region. In order to understand the reasons for this on a musicological level, in Figure 16 we have separated the contributions of each voice group to the F0 value histogram in form of a stacked histogram. 


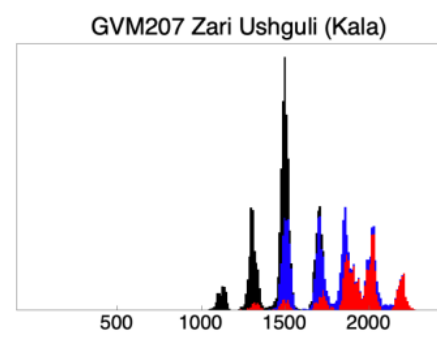

a)

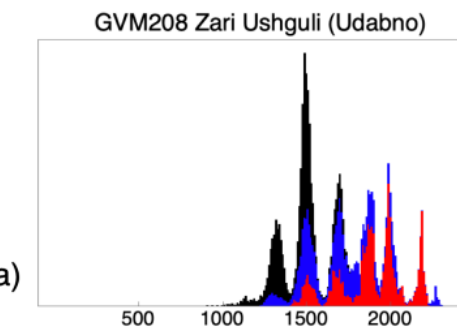

d)
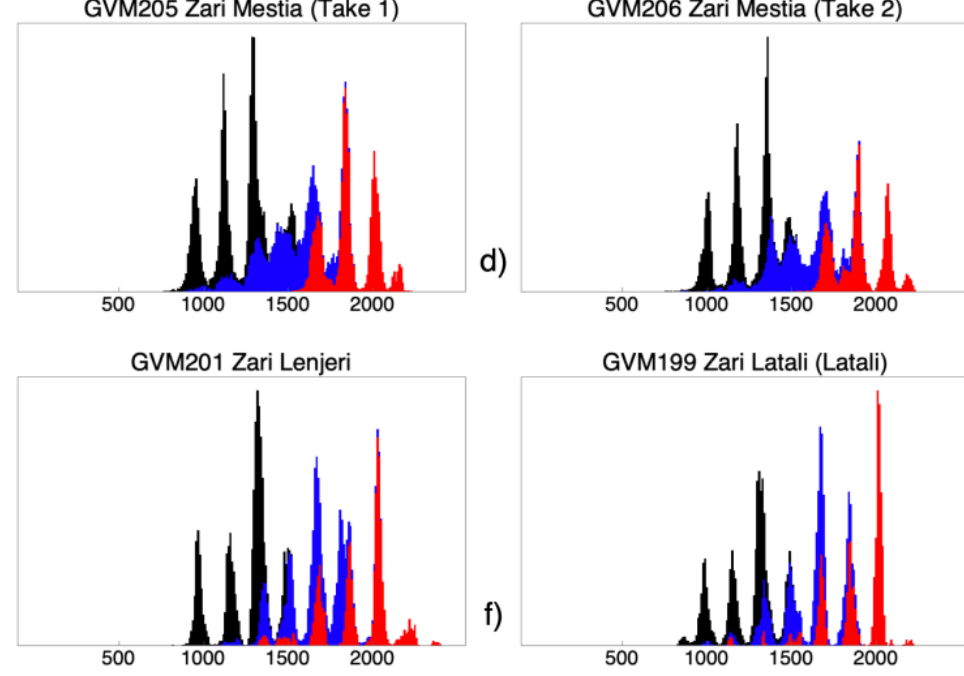

GVM202 Zari Lower Bal (Etseri)

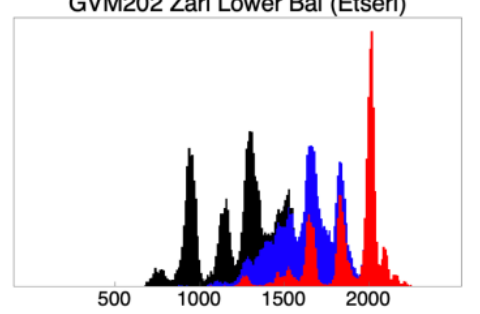

GVM199 Zari Latali (Latali)

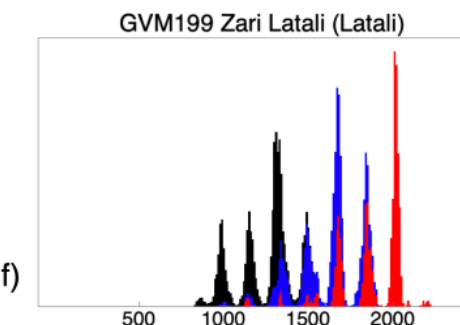

GVM203 Zari Lower Bal (Latali)

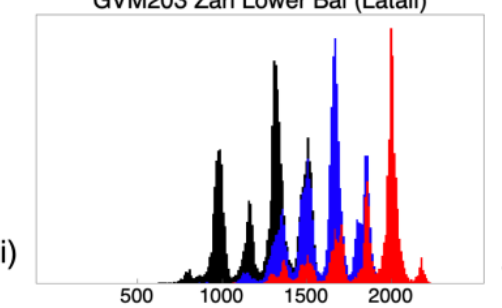

GVM198 Zari Kala

b)

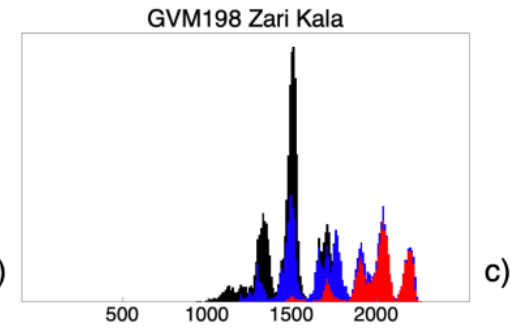

e)

g)

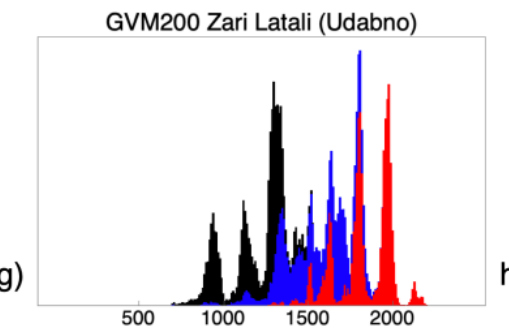

h)

GVM204 Zari Lower Bal (Tsalka)

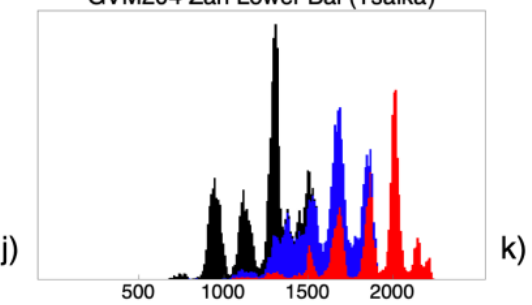

Figure 16. Stacked F0 histograms in which the height of each histogram bin corresponds to the sum of the contributions of all voices. Black, blue and red correspond to the contributions of the bass, the middle and the top voice pitches, respectively. The units of the horizontal axis are cents with respect to a reference frequency of $110 \mathrm{~Hz}$.

Figure 16 reveals some common properties of all zär, but also illustrates differences that make them individual and unique. The first and most important difference is in the 'weight'16 of the individual pitch categories and how it is distributed over the histogram. For the Ushgul and K'âl variant (Figure 16a-c), one can see that there is a single pitch category, centered at 1500 cents, which carries a very large weight, while all the other categories have a much lower weight. In the Mest'ia variant (Figure 16d-e), the pitch category centered around 1300 cents is the most prominent, but it does not stick out as

\footnotetext{
16 Mathematically, the weight of an individual pitch category can be defined as the area under the corresponding pitch group, divided by the total area under the full histogram. This corresponds to the relative duration with which the corresponding pitch category is heard in that variant. E.g. a weight of 0.1 would mean that the corresponding pitch is heard for $10 \%$ of the total duration.
} 
much from the other categories than in the case of the Ushgul and K'āl variants. Finally, in the case of the other variants (Figure 16f-k), the weights become even more equally distributed over all categories. In addition, the pitch inventory range also differs. It gradually expands, as we move down from Ushgul to Lower Bal. As a consequence, individual voices have more options to move. Thus, more and more pitch categories are used, which results in a more even distribution of weights.

The F0 value histograms in Figure 16 show that category boundaries can either be clearly separated from each other as in Figure 16a-c, or can penetrate each other, depending on 'who' performs, but also which voice. In particular, the contributions from the middle voice (blue) often show very blurred category boundaries.

Based on the combined aural transcription-based analysis from this part of our study and the acoustical analysis described in paper 1 , we can draw some conclusions regarding the functional roles of some of the individual pitch categories. In the variants of K'âl-Ushgul (Figure 16a-c) example, the pitch category centered at 1500 cents, after being initiated and confirmed by the introductory call, is maintained by the bass voice throughout the chant. Because of the way the pitch drift correction in paper 1 was done, the pitch category centered at 1500 cents is always the pitch category of the final note. Sometimes, upper voices merge with it at moments that mark the endpoints of a structural pattern (c.f. Figure 10, part 1). This makes it the stable pitch throughout the dirge and designates it as the main tonal center (MTC). In other variants, however, it can be observed that the peak at 1500 cents loses its dominance and the most prominent peak, in terms of weights, is observed slightly above 1300 cents. The reason for this is that the main tonal center shifts to one pitch category below the final note. If in the K'āl-Ushgul variant, the main tonal center remains until the end of the chant, in all other variants it changes to the final pitch category only at the end. This is clearly visible in Figure 16 in the shift of the highest peak of the bass voice contributions between Figure 16a-c and Figure 16d-k. In other words, there is no difference between these variants on the functional level, as the main tonal center retains its role and function throughout the dirge, although in Figure 16a-c the main tonal center has a center pitch of 1500 cents, while in the other variants - a center pitch of about 1300 cents. 
Figure 16 also clearly demonstrates that the differences in the pitch inventories for different zär variants depend obviously not on the 'what' (which variant) the groups perform, but on the 'who' (which group) performs them (c.f. Figure 16g-h for the Latal Figure 16i-k for and the Lower Bal variant). However, in all variants some pitch categories are always very similar in shape and weight and show clearly separated category boundaries. This is first of all true for the pitch categories below the main tonal center or for the temporary tonal centers. We believe that this is due to the function of these lowpitched tones both within the whole song and inside the phrases. They seem to serve within cadence structures and are, therefore, most stable and clear at the individual tone level as well.

Another reason for the diversity of the shapes of the pitch inventories within the higher pitch ranges, is the effect of the vertical conditions. In other words, singers adjust their melodic steps to the harmonic intervals to be achieved.

To conclude the issue of the melodic tonal organization, although the pitch inventories in Figure 16 are well-defined, their dependence on 'who' performs them does not allow to introduce a single zär tuning system for all recorded performances.

\section{Harmonic interval inventories}

From the harmonic perspective, the most prominent features are a) an abundance of parallel fifths, which occur in all variants and which are realized without exception by all ensembles, and b) the perceptionally also very strong, although not so frequent, parallel fourths between the bass and the middle voice. Whenever they occur concomitantly, they generate the 1-4-5 chord, which is considered to be the hallmark of Georgian traditional music (with a major second as byproduct). This happens in all zär variants, as can be seen in Figure 17. This demonstrates that both fourths and fifths are very strong concepts for Svans, despite minor fluctuations, which depend on who performs. 

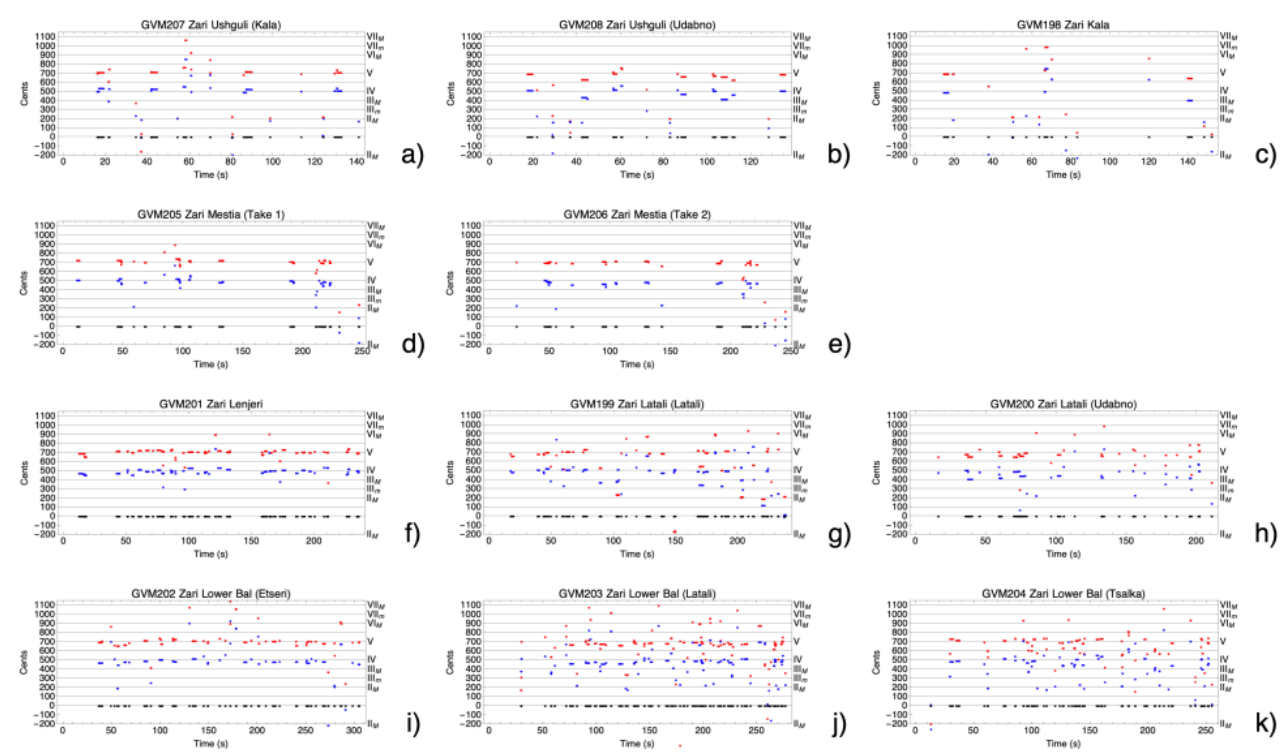

Figure 17. The appearance of harmonic fourths in any of the voice combinations. All note tracks have been corrected for the bass voice pitches (black). As a consequence, the bass voice interval appears at 0 cents. Red and blue correspond to the top and middle voices, respectively.

In contrast, one can observe abundant applications of different degrees of thirds, the size of which ranges somewhere between 300 and 400 cents. This demonstrates that the concept of thirds is not based on a single interval size. This can be nicely seen for example in Figure 18d-e.
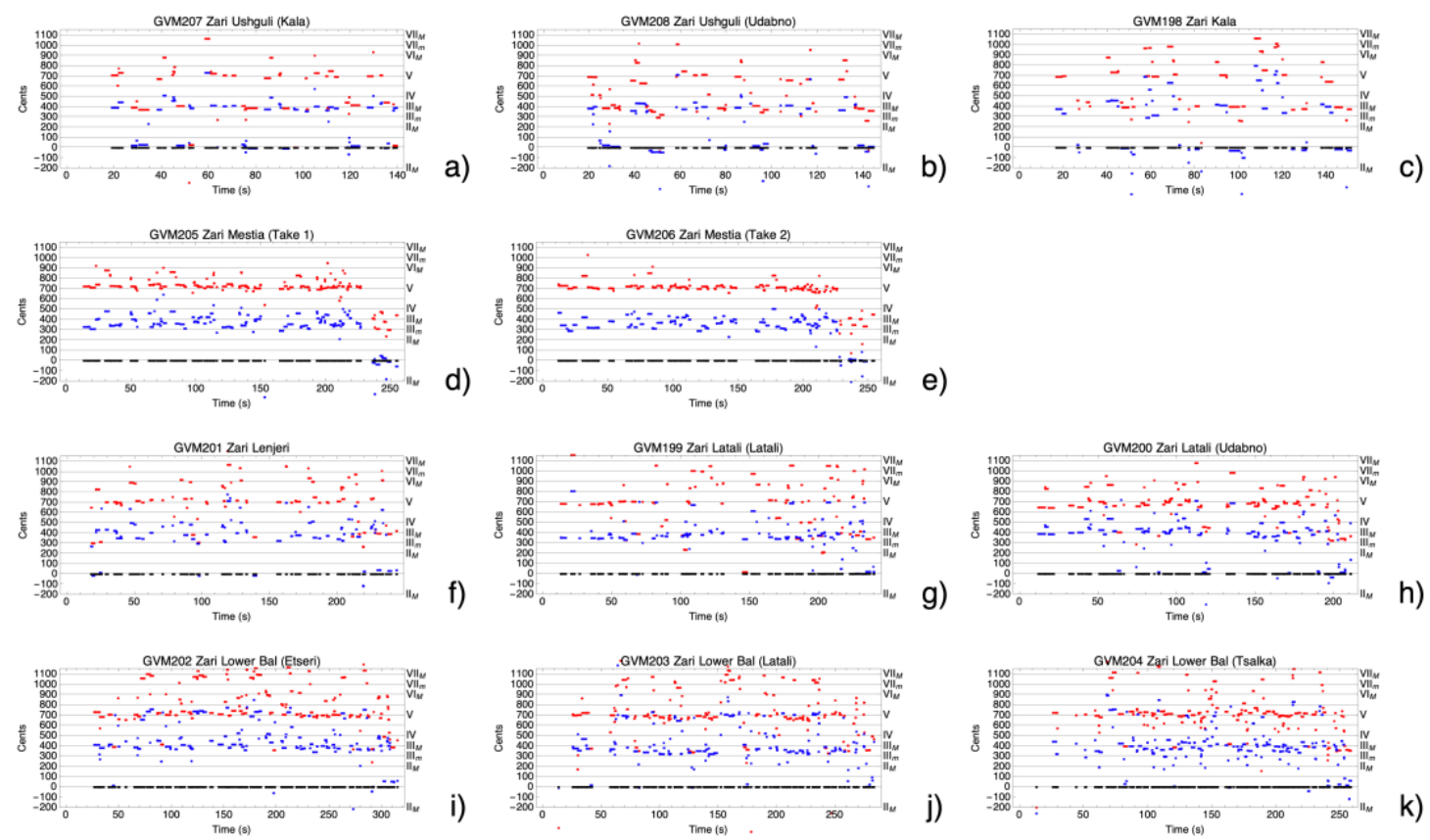

Figure 18. The appearance of harmonic thirds in any of the voice combinations. 


\section{Along the course of the Enguri river}

One of the most striking results of our study, both from the acoustical, as well as from the perceptional perspective, is the systematic change of the musical properties along the course of the Enguri river. Below, these properties are discussed in detail, following the course of the river from the highest altitude to the lowest for the individual variants.

\section{K'äl-Ushgul zär}

In general, the inventory of harmonic intervals varies from the unison to the fifth, which serve as the main building material for the musical (harmonic) texture. As for very few sixths and sevenths, they seem to have melodic origin (see also Figure 8 of paper 1).

The music of the dirge is based on very slow and synchronous movements of all three voices, resolved in the main tonal center in unison. Thus, there is no voice that shows a hierarchical dominance, in terms of the development of the melody. Therefore, the inventory of harmonic intervals remains the same, including in cadences. But every once and again, the upper or bass voice 'ornaments', i.e., makes a bigger or additional step, which slightly changes the vertical structure and leads to a wider interval between the upper and bass voices.

The K'āl-Ushgul variant is a perfectly harmonious texture. It does not allow one to grasp a melody, except for the introductory call. However, it demonstrates a modest attempt to break the boundaries of fixed harmonic frames and explore neighboring areas.

An important difference between the K'âl-Ushgul and all the other variants of zär is the application of the unison interval. The prevalence of unison in the K'âl-Ushgul variant indicates a peculiarity of its compositional form, based on closed phrases (main tonal center or a temporary tonal center). As for the other variants described below, the significantly reduced number of unisons demonstrates different forms of cadences. This means that, in most cases, phrases are resolved in open cadences and musical development is therefore open/continuous as discussed earlier.

\section{Mest'ia zär}

In the Mest'ia variant, the absolute dominance of the pure fifth (see e.g., Figure $6 \mathrm{~d}$ and e of paper 1 ) is due to the tendency of the upper voice to move in parallel with the bass 
voice, which goes down and explores new steps below (c.f. Figure. 8d and e of paper 1). In contrast to the K'âl-Ushgul zär, the cadences in the Mest'ia variant are not closed (voices do not meet at unison), and phrases grow into each other through open ends. In other words, temporary tonal centers (TTC) are not emphasized by cadenzas. However, the ornamentation, which in the K'àl-Ushgul variants of zär occurs in very small, 'embryonic' form, develops further in the Mest'ia and also in the Lower Bal variant discussed below.

What is most striking in the Mest'ia zär, is the number and diversity of harmonic thirds employed. The fourths are mainly heard in the cadence parts of the phrases. Although the fourth is hidden under the shadow of a very dispersed third in Figure 6d-e of paper 1, the concept of the former is as clear as that of the fifth as can be seen Figure $17 \mathrm{~d}$ and e.

\section{Lenjār, Lat'li and Lower Bal variants}

Moving to the Lenjār region and further down the Enguri river, the musical texture, both horizontally and vertically, is expanding and becoming increasingly sophisticated.

The Lenjār zär shows great dedication to the combination of the fourth and the fifth, in other words to the 1-4-5 chord so characteristic of traditional Georgian music (c.f. Figure 17f). Here we see how far the bass starts to move, which leaves a wider space between the bass and the middle part, allowing the middle part to freely oscillate between different realizations of the interval of the third (Figure 6i-k, paper1). At the same time, middle and top voices explore higher pitch ranges, leading to harmonic sevenths and the sixths. We believe that these intervals are of melodic origin, that is, singers try to develop more freely and find new ways of expression.

This tendency is growing and extends even to wider intervals in the Lower Bal variant. In other words, from time to time, the melody (horizontal development) takes over the harmonic (vertical) dominance, in order to communicate the intended musical idea.

The zär variants sung by the Lenjār and Lat'li groups show very well-defined harmonic interval categories, including thirds and fourths. This can be explained by the fact that 
most of the singers of Lenjār and Lat'li groups are members of the Riho choir, led by Islam Pilpān, who has been the leading master of Svan songs for decades ${ }^{17}$.

Similar to the Mest'ia zär, the prevalence of the harmonic thirds and their diversity for the Lower Bal variant of Etseri and Ts'alk'a villages (Figure 6i-k, paper 1) somewhat overshadows the fourths in the interval distributions, although they are clearly present and well-defined at certain times in the dirges (c.f. Figure 17i-k).

\section{What about introductions?}

In all the discussions about the musical properties and how they might reflect contextual information such as the geographical location, which, in turn, is affecting other aspects such as settlement history etc, we have not really touched upon the monophonic introductions, which precede all zär, and which set the stage for the subsequent polyphonic part in several respects. They seem to bear the whole concept of the chant, both in musical and verbal aspects.

However, despite the fact that each call is a variant specific (in other words, each call indicates which zär will be performed), the analysis of monophonic calls revealed melodic formulas (templates), which are associated with some other songs from not mourning, but still ritual (sacred) repertoire with a hymn-type musical structure and vague verbal (or mainly syllabic and vowel) content. For example, the monophonic call of K'àl-Ushgul $z \ddot{a r}$ is either identical to the introduction of the hymn-type 'songs', such as Lile, K'wiria, and Elia lorde (GVM198 and 208), or repeats the melodic contour with slightly different degrees of pitches or pitch categories of constituent steps (GVM207) (Figure 3, paper 1).

\footnotetext{
17 Islam Pilpān was not only a folk singer, but also had a classical musical education.
} 


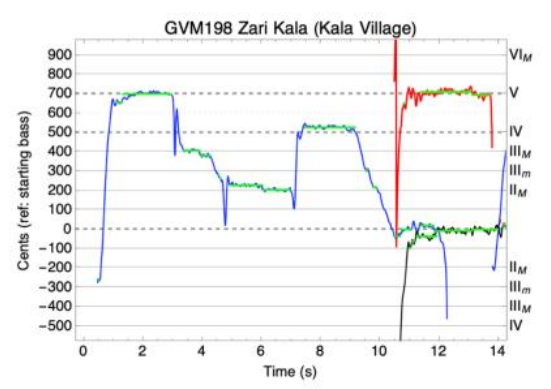

a)
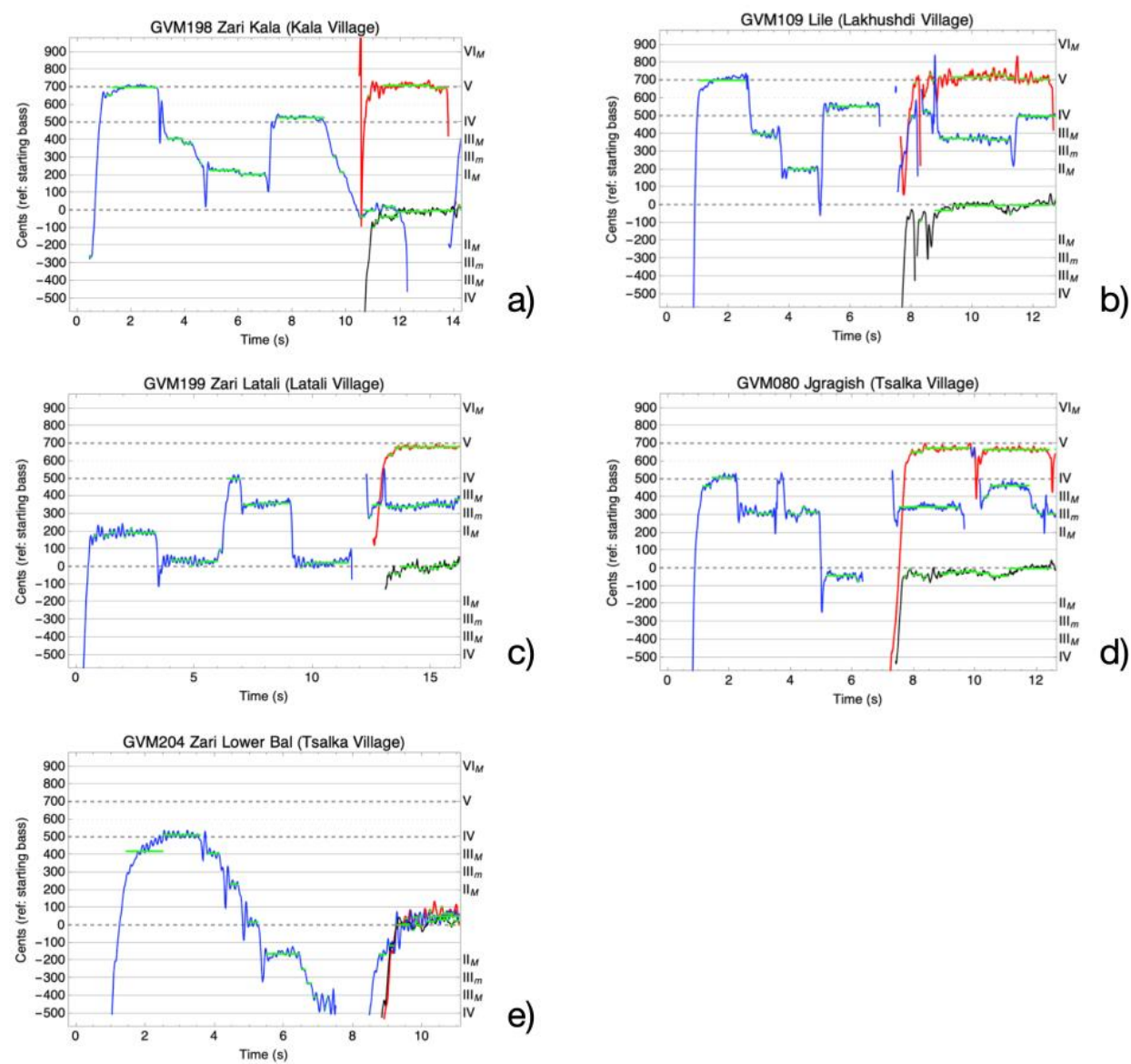

e)

Figure 19. Introductory calls for different variants of zär and some selected hymn-type songs.

As for the variant of Lower Bal, it seems to repeat the melodic contour of the K'âl-Ushgul call, develops it, and extends the range of the pitch inventory. Here we can say that it is also based on the melodic formulae of the above-mentioned hymn-type repertoire.

Similarly, the introduction of the Lat'li zär (GVM199, 200) reproduces the melodic (also verbal) pattern of other hymns such as, for example, Lower Bal zär and 'Tskhaw Krisdēsh'. Such repetition of the tune raises the question of how it turns out that two different genres use the theme of a dirge, which is considered a bad sign (attracting misfortune) if performed at any time except for the funeral. This similarity is particularly striking when the verbal text is also repeated in the context of a funeral (Lat'li zär and 'Jgarägish'). Here ethnographic reports come to the aid, which claim that zär was performed only at the funeral of the happy deceased (Arakishvili, 1950: 23l; Akhobadze, 1957: 21) and that the chant contained words of praise. In general, it made an impression of a solemn hymn. 
As for the calls of the Mest'ia and the Lenjār zär, although they look similar at first glance, it seems that even a small difference matters and gives each of them an individual signature. However, obviously, it has a more individualistic development within a threepart structure.

As mentioned above, the introduction signals which zär will be offered, which tone will be the main tonal center and which range of vertical-horizontal movements will be used as the framework. For example, the K'âl-Ushgul variant has its own melodic call that extends into a small (short) range and covers only five pitches, of which the ending tone is the tonal center to which the bass voice gets connected (Figure 10a, paper 1). This reference pitch is 1500 cent and remains stable throughout the whole dirge. If we compare the same zär variant in the performance of the Udabno and K'āl groups, we will see that some of the pitches of the call sound in different degree (color), which makes us assume that performers are free to manipulate some pitches and replace one category with another (Figure 10b, c), but the main tonal center, together with pitches, which make the melodic intervals of the fourth and the fifth, remain intact ${ }^{18}$.

As we move from Ushgul down to the Mest'ia Valley, and even further towards Lower Bal, the calls become more complex, expanding in range and using more area around the basic pitch framework. Accordingly, the movement space for each individual part is also increasing. A very vivid example of this is the Lower Bal variant from Ts'alk'a. The call range reaches seven steps and even uses almost every step within the range, giving a signal about what the scale will look like. In addition, it contains the structural features of the entire dirge, which represents a much more advanced and complex (sophisticated) composition than other zärs. It provides a kind of space for the group to take advantage of this opportunity. Thus, we can see how the vertical (harmonic) inventory is broadened, and how voices are expanding and developing in the proposed space. In addition, in the Lower Bal variants, the call also models the final modulation up by one step, thus already covering (embracing) the tonal frame of the entire dirge (Fig. 10).

\footnotetext{
18 There are insignificant but still some differences (related to mild ornamentation and articulation aspects) between the recordings of the Ushgul group on one side, and the K'āl and Udabno groups, on the other (although in fact both belong to the same variant). The identical recordings of K'âl and Udabno group can be explained by the fact that one of the leading singers of the group of Udabno (eco-settlement of Svans near Tbilisi) emigrated from K'āl and, obviously, practiced this variant with his fellow singers from Udabno, who mainly emigrated from Lat'li.
} 
This discussion of zär's compositional structure, including the introduction, as we can see, outlines the form of its musical idea and shows that each larger structural unit (built via phrases and motifs) helps shape its musical narrative. At the same time, each phrase (motif) itself is formed with the help of musical 'ingredients,' including horizontal (melodic) and vertical (harmonic) tones and intervals. Therefore, the study also focuses on the tonal (both horizontal and vertical) organization of zär, which we will briefly review (discuss) below.

\section{Discussion and conclusions}

With the present study, in which we have combined a computational/acoustical perspective (Scherbaum \& Mzhavanadze, 2020) and a classical musicological view (this paper), we have attempted to contribute to a better understanding of Svan funeral dirges. To us, three aspects seem worth mentioning in this context.

First, the results of the acoustic analysis and the results of the musicological structural analysis, both show very clear relationships to the settlement history of Svans along the Enguri River, which obviously reflects in the music of the Svans in a systematic way. As we have demonstrated in paper 1 , the ambitus, duration, and complexity of the harmonic and melodic structure of zär systematically change along the course of the Enguri river. In this paper we see that this tendency is also manifested in the complexity of the compositional structure, which is formed according to two main compositional principles: repetition (most simple variant) and elaboration (advanced variants). The K'āl and Ushgul communities, as the most remote settlements in Upper Svaneti, were separated from the rest of the region for almost six months during the year because of the harsh climate, and therefore led a more closed lifestyle. Their variant seems to represent all the structural building blocks and building principles of Svan zär in an embryonic form: A-B-A-B. As for the variants of settlements further downstream, such as Mest'ia, Lenjār, Lat'li, and Lower Bal, the phrases are not only repeated, but also elaborated and enriched with new phrases and coda: A-B-C-A1-B1-coda. Compared to the K'âl-Ushgul variant, the complexity of the intra-phrasal structure and ambitus significantly increases, which seems to indicate a greater desire for melodic (horizontal) development. We believe this development may be due to intensive communication and closer exposure to the neighboring musical dialects of western Georgia. At the same time, although this more 
complex musical texture manifests itself in the highly developed and complex use of harmonic and melodic elements, the original skeleton is preserved and can be found by analysis.

The second aspect concerns tonal organization. While the harmonic interval inventory for all zär variants is consistently identifying the unison, fourth, and fifth as stably defined interval concepts, this is not the case for the third, which appears as a poorly defined pitch category with a large dispersion (spread). Regarding the melodic interval inventory, which could only be determined after correcting the F0 trajectories for the gradual but non-consistent pitch-drift observed for almost all of the variants, it turned out that the existence of a single zär tuning system is very unlikely. Instead, tuning system used depends more on WHO makes the zär than WHAT (which variant) is performed.

Finally, we see the most interesting aspects of our study in the consequences that arise for the discourse on the origins of Georgian polyphony widely discussed over decades by Georgian music scholars (Arakishvili, 1950; Aslanishvili, 1954; 2010; Gogotishvili 1994; Chkhikvadze, 2010; Chokhonelidze, 2010; Gabisonia, 2006; Javakhishvili, 2010; Khardziani, 2003). There are two different lines of thought on this topic, the first of which is associated with the evolutionary development of monophony into a three-part polyphony. This theory is discussed in more detail in two models. The first one, which we call the 'fourth model', goes back to Aslanishvili (1954). According to this model, Svans' three-part music initially developed from unison into two-part music (with the fourth as core interval), to which later on an upper voice was added that moves parallel to the bass voice in a fifth ${ }^{19}$.

The second model proposed by Gogotishvili (1994), we would call the 'fifth model'. In the 'fifth model' the first voice is the upper one, to which the second voice is added at the bottom. The voice added here as the third voice is the middle voice, which is a fourth above the bass voice.

In contrast to the evolutionary models, Ficker (1929) and, more recently, Jordania (2006, 2010) suggested that polyphony can be an original form of musical creativity. Ficker (1929) has argued that polyphonic sounds are an indispensable part of any natural

${ }^{19}$ This is the main theory, which is still shared by most Georgian ethnomusicologists. 
soundscape and therefore should be considered as a primary sound form. Jordania (2006, 2010) has suggested that group singing was part of the original pre-human communication with great advantage for survival.

As for zär, the results of our analysis cannot be explained by any of the stadial development hypotheses, in which a 'melody voice' is augmented by additional voices in order to create the vertical structure. First of all, none of the zär voices take the role of a melody, except for the middle voice in the monophonic introductory call. For the K'âlUshgul zär for example, the harmonic fourth, the core interval in Aslanishvili's hypothesis, appears only intermittently, starting at about 20 seconds within the dirge (Figure 18a), while the harmonic framework of parallel fifths between the bass and the top voice is established immediately at the beginning of the polyphonic part (Figure 8a, paper 1). Figure 8a also shows that the middle voice in the polyphonic part wanders in a highly variable (in terms of harmonic intervals) fashion between the top and bass voices, without building a stable harmonic relationship between either of the voices. Gogotishvili's (1994) hypothesis is also inconsistent with our results, since the harmonic framework of parallel fifths starts only after the middle voice has finished its introductory call. In addition, the fourth seems to have semantic meaning to intensify the expression of pain and grief. In zär, it comes with the interjection of wai, which is specific to the funeral context. Therefore, it seems unreasonable to assume that the middle voice was added later. Finally, as a crucial argument against both evolutionary models, the tonal center, around which the whole musical structure is built on, is maintained by the bass voice, which is actually ruled out by both evolutionary models as a primary voice.

To conclude:

- For all zär variants and all zär performances in our collection, we found a strong harmonic framework of parallel fifths between the bass and the top voice.

- In $z \ddot{r}$, the fourth seems to have a semantic meaning to enhance the mourning expression.

- The acoustic features and the compositional structure of the various zär variants are closely linked to the geographical location of their origin along the Enguri River. 
- The systematically increasing complexity of the various zär variants downstream the Enguri River reflects the increasing influence of the neighboring non-Svan music styles.

- As for the origin of zär, we believe that all the results of our analysis exclude evolutionary models at least in its supposedly oldest living tradition associated with the notion of 'death and pain of loss'. The strong presence of pure harmonic intervals in the highly conceptual harmonic structure suggests that the three-part texture of zär most likely represents its original form.

Finally, we would like to speculate about the strong presence of fifths and fourths in zär. Fifths and fourths together seem to embody the simultaneous realization of overtone frequencies as a physical property of nature, as an original sound form (Ursprüngliche Klangform) in the sense of Ficker (1929), or in the words of Reck (1977), in that 'the pure relationships of overtone sequences... are reflected in the harmony all over the world'. In that sense, we believe that Svan zär is a vivid demonstration of how the natural law manifests itself in the musical 'thinking' of the man.

\section{Acknowledgements}

This work was supported by the German Research Foundation within the framework of the project Computational Analysis of Traditional Georgian Vocal Music (GVM) (DFG MU 2686/13-1, SCHE 280/20-1). First and foremost, our gratitude goes to all the people during the 2016 field expedition who allowed us to be part of and record their rituals. We are thankful to Meinard Müller and his team for the stimulating collaboration as well as for hosting the web-based repository of the GVM data. We would like to thank Nino Sadradze for providing the GIS shape files for Svaneti and Susanne Ziegler and Simha Arom for their comments on the manuscript.

\section{REFERENCES}

Akhobadze, Vladimer. (1957). Kartuli (Svanuri) Khalkhuri Simgherebi [Georgian (Svan) Folk Songs]. Tbilisi: T'eknik'a da Shroma. 
Arakishvili, Dimitri. (1950). Svanuri Khalkhuri Simgherebi [Svan Folk Songs]. Tbilisi: Khelovneba.

Arom, Simha; Vallejo, Pollo. (2010). "Towards a Theory of the Chord Syntax of Georgian Polyphony." [The Fourth International Symposium on Traditional Polyphony] Eds. Rusudan Tsurtsumia and Joseph Jordania: pp. 321-335. Tbilisi: International Research Center for Traditional Polyphony of Tbilisi State Conservatoire (in Georgian and English). Aslanishvili, Shalva. (2010). "Forms of Multipart Singing in Georgian Folk Songs." Echoes from Georgia: Seventeen Arguments on Georgian Polyphony, Eds. Rusudan Tsurtsumia and Joseph Jordania: pp. 57-81. Nova Science Publishers, Inc.

Aslanishvili, Shalva. (1954). Nark'vevebi Kartuli Khalkhuri Simgherebis Shesakheb [Essays on Georgian Folk Songs]. Vol. I (in Georgian). Tbilisi: Khelovneba.

Chkhikvadze, Grigol. (2010). "Main Types of Georgian Folk Polyphony.” Echoes from Georgia: Seventeen Arguments on Georgian Polyphony, Eds. Rusudan Tsurtsumia and Joseph Jordania: pp. 97-110. Nova Science Publishers, Inc.

Chokhonelidze, Evsevi. (2010). "Some Characteristic Features of the Voice Coordination and Harmony in Georgian Multipart Singing". Echoes from Georgia: Seventeen Arguments on Georgian Polyphony, Eds. Rusudan Tsurtsumia and Joseph Jordania: pp. 135-45. Nova Science Publishers, Inc.

Ficker, Rudolf von. (1929). "Primäre Klangformen" [Primary forms of sound]. Jahrbuch Der Musikbibliothek Peters, Leipzig, 21-35.

Gabisonia, Tamaz. (2006). "Hypotheses about the Process of the Formation of Georgian Polyphonic Singing." [The Second International Symposium on Traditional Polyphony] Eds: Rusudan Tsurtsumia and Joseph Jordania: pp. 73-78. Tbilisi: International Research Center for Traditional Polyphony of Tbilisi State Conservatoire (in Georgian and English).

Gabisonia, Tamaz. (2007). Kartuli t'raditsiuli mravalkhmianobis pormebi [Forms of Georgian Traditional Polyphony]. Tbilisi State Conservatoire. Retrieved from http://eprints.iliauni.edu.ge/9195/. 
Gogotishvili, Vladimer. (1994). "Svanuri Sagundo Mravalkhmianobis Pakturuli Taviseburebebis Sak'itkhisatvis" [On the Issue of Structural Peculiarities of Svan Choral Polyphony]. Issues of Musicology. Scientific Works, Ed. Rusudan Tsurtsumia: 3-39. Tbilisi: Tbilisi State Conservatiore.

Javakhishvili, Ivane. (2010). "The Views and Theories of Georgian Authors.” Echoes from Georgia: Seventeen Arguments on Georgian Polyphony, Eds. Rusudan Tsurtsumia and Joseph Jordania: pp. 19-34. Hauppauge, N.Y: Nova Science Publishers, Inc. http://www.novapublishers.com.

Jordania, Joseph. (2010). “Georgian Traditional Polyphony in Comparative Studies: History and Perspectives." Echoes from Georgia: Seventeen Arguments on Georgian Polyphony, Ed. Tsurtsumia, Rusudan and Joseph Jordania: pp. 229-48. Hauppauge, N.Y: Nova Science Publishers, Inc. http://www.novapublishers.com.

Jordania, Joseph. (2006). Who Asked the First Question? The Origins of Human Choral Singing, Intelligence, Language and Speech. Ed. Matthews Grant. Logos.

Khardziani, Maka. (2003). "Formation of Three-Part Singing and Determination of the Type of Polyphony in Svanetian Traditional Music." [The First International Symposium on Traditional Polyphony]. Eds Rusudan Tsurtsumia and Joseph Jordania: pp. 330-334. Tbilisi: International Research Center for Traditional Polyphony of Tbilisi State Conservatoire (in Georgian and English).

Kholopov, Yuri. (1985). "K probleme muzikalnogo analiza” [To the Problem of Musical Analysis, 1974]. Problemi muzikalnoi nauki [Problems of Musical Science]. 6: 130-151. Moscow: Soviet Composer.

Mazel, Lev Abramovich. (1960). Stroenie muzykal'nykh proizvedeniı̆ [Structuring of the Music Works]. (2nd ed). Moscow: Muzika.

Mazel, Lev Abramovich; Zuckermann, Viktor Abramovich. (1967). Analiz muzykal'nykh proizvedeniŭ: Elementy muzyki i metodika analiza malykh form [Analysis of Musical Works: Elements of Music and a Methodology of Analysis of Small Forms]. Moscow: Muzika. 
Mzhavanadze, Nana; Scherbaum, Frank. (2020). "Svan Funeral Dirges (Zär): Cultural context", LaZar Database (https://lazardb.gbv.de).

Paliashvili, Zakaria. (1909). Kartuli Khalkhuri Simgherebis K'rebuli. Imeruli, Guruli, Rach'uli, Svanuri da Kartl-K'akhuri [Collection of Georgian folk songs: Imeretian, Gurian, Rach'an, Svan and Kartl-K'akhetian]. Tbilisi: Tpilisis Kartuli Pilarmoniuli Sazogadoeba N5.

Reck, David. (1977). Music of the Whole Earth. New York: Charles Scibner's sons.

Scherbaum, Frank; Mzhavanadze, Nana. (2020). "Svan Funeral Dirges (Zär): Musical Acoustical Analysis of a New Collection of Field Recordings." Musicologist. 4(2): 138-167.

Scherbaum, Frank; Mzhavanadze, Nana. (2018). "A New Archive of MultichannelMultimedia Field Recordings of Traditional Georgian Singing, Praying, and Lamenting with Special Emphasis on Svaneti." LaZAR-Database. https://Lazardb.Gbv.de/.

Zuckermann, Viktor Abramovich. (1970). "O nekotorykh osobykh vidakh tselostnogo analiza" [On Several Particular Kinds of Holistic Analysis]. Muzykal'no-teoreticheskie ocherki i etiudy [Musical-Theoretical Essays and Studies], 409-26. Moscow: Sovetskiŭ Kompozitor. 